\title{
Daily variations of gut microbial translocation markers in ART-treated HIV-infected people
}

Jing Ouyang ${ }^{1,2,3 \dagger}$, Stéphane Isnard ${ }^{1,2 \dagger}$, John Lin 1,2, Brandon Fombuena ${ }^{1,2,4}$, Debashree Chatterjee, Tomas Raul Wiche Salinas ${ }^{5,6}$, Delphine Planas ${ }^{5,6}$, Amélie Cattin ${ }^{5,6}$, Augustine Fert ${ }^{5,6}$, Etiene Moreira Gabriel ${ }^{5,6}$, Laurence Raymond Marchand ${ }^{5}$, Yonglong Zhang ${ }^{7}$, Malcolm Finkelman ${ }^{7}$, Yaokai Chen ${ }^{3}$, Daniel E. Kaufmann ${ }^{5,6}$, Nicolas Cermakian ${ }^{8}$, Petronela Ancuta ${ }^{5,6}$ and Jean-Pierre Routy ${ }^{1,2,9^{*}}$ (D)

\begin{abstract}
Background: Increased intestinal barrier permeability and subsequent gut microbial translocation are significant contributors to inflammatory non-AIDS comorbidities in people living with HIV (PLWH). Evidence in animal models have shown that markers of intestinal permeability and microbial translocation vary over the course of the day and are affected by food intake and circadian rhythms. However, daily variations of these markers are not characterized yet in PLWH. Herein, we assessed the variation of these markers over $24 \mathrm{~h}$ in PLWH receiving antiretroviral therapy (ART) in a well-controlled environment.
\end{abstract}

Methods: As in Canada, PLWH are predominantly men and the majority of them are now over 50 years old, we selected 11 men over 50 receiving ART with undetectable viremia for more than 3 years in this pilot study. Blood samples were collected every $4 \mathrm{~h}$ over $24 \mathrm{~h}$ before snacks/meals from 8:00 in the morning to 8:00 the next day. All participants consumed similar meals at set times, and had a comparable amount of sleep, physical exercise and light exposure. Plasma levels of bacterial lipopolysaccharide (LPS) and fungal ( $\rightarrow 3$ )- $\beta$-D-Glucan (BDG) translocation markers, along with markers of intestinal damage fatty acid binding protein (I-FABP) and regenerating islet-derived protein-3a (REG3a) were assessed by ELISA or the fungitell assay.

Results: Participants had a median age of 57 years old (range 50 to 63). Plasma levels of BDG and REG3a did not vary significantly over the course of the study. In contrast, a significant increase of LPS was detected between 12:00 and 16:00 (Z-score: $-1.15 \pm 0.18$ vs $0.16 \pm 0.15, p=0.02)$, and between $12: 00$ and $24: 00(-1.15 \pm 0.18$ vs $0.89 \pm 0.26$, $p<0.001)$. The plasma levels of I-FABP at 16:00 $(-0.92 \pm 0.09)$ were also significantly lower, compared to 8:00 the first day $(0.48 \pm 0.26, p=0.002), 4: 00(0.73 \pm 0.27, p<0.001)$ or $8: 00$ on secondary day $(0.88 \pm 0.27, p<0.001)$.

Conclusions: Conversely to the fungal translocation marker BDG and the gut damage marker REG3a, time of blood collection matters for the proper evaluation for LPS and I-FABP as markers for the risk of inflammatory non-AIDS comorbidities. These insights are instrumental for orienting clinical investigations in PLWH.

\footnotetext{
*Correspondence: jean-pierre.routy@mcgill.ca

${ }^{\dagger}$ Jing Ouyang and Stéphane Isnard contributed equally to the study

${ }^{1}$ Infectious Diseases and Immunity in Global Health Program, Research

Institute, McGill University Health Centre, 1001 Blvd Décarie, Montreal,

QC, Canada

Full list of author information is available at the end of the article
}

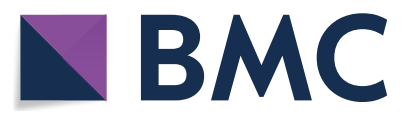

(c) The Author(s) 2020. This article is licensed under a Creative Commons Attribution 4.0 International License, which permits use, sharing, adaptation, distribution and reproduction in any medium or format, as long as you give appropriate credit to the original author(s) and the source, provide a link to the Creative Commons licence, and indicate if changes were made. The images or other third party material in this article are included in the article's Creative Commons licence, unless indicated otherwise in a credit line to the material. If material is not included in the article's Creative Commons licence and your intended use is not permitted by statutory regulation or exceeds the permitted use, you will need to obtain permission directly from the copyright holder. To view a copy of this licence, visit http://creativeco mmons.org/licenses/by/4.0/. The Creative Commons Public Domain Dedication waiver (http://creativecommons.org/publicdomain/ zero/1.0/) applies to the data made available in this article, unless otherwise stated in a credit line to the data. 
Keywords: Daily variation, Microbial translocation, $(1 \rightarrow 3)-\beta-D-G l u c a n$, Gut damage, HIV

\section{Background}

The gastrointestinal tract is a distinctive tissue with physical, biological and immunological barriers, allowing nutrient absorption while preventing the translocation of microbes and their products. HIV infection is associated with modification of the gut microbiota, disruption of the gut epithelial barrier, and increased intestinal permeability [1-4]. In contrast to the global health improvement occurring in people living with HIV (PLWH) receiving antiretroviral therapy (ART), gut damage persists and translocation of microbial products from the gut lumen into the circulation contributes to inflammatory non-AIDS comorbidities [5]. Microbial translocation is one of the main drivers for the development of such comorbidities including cardiovascular disease, depression and cancer in ARTtreated PLWH [6-10].

Measurement of microbial translocation plasma markers have been frequently performed in studies evaluating therapeutic interventions and assessing the risk of developing non-AIDS co-morbidities [11-27]. Circulating levels of lipopolysaccharide (LPS) are commonly measured to assess the level of bacterial translocation. LPS is a bacterial cell wall polysaccharide and is a well-known inducer of innate immune activation [13]. Besides bacterial translocation, there is increasing awareness regarding fungal translocation [24, 28-30]. Fungi contribute greatly to opportunistic infections in PLWH, including Pneumocystis jirovecii in the respiratory tract and Candida albicans in the gastrointestinal tract [31]. $(1 \rightarrow 3)-\beta-D-$ Glucan (BDG) is a major component of most fungal cell walls and serves as a potent pathogen-associated molecular pattern (PAMP) in triggering antifungal immunity [32]. Circulating BDG is currently used for the clinical diagnosis of Candida, Aspergillus, and Pneumocystis jirovecii invasive infections [33]. Recently, we and others have found that plasma levels of BDG are associated with epithelial gut damage and risk of developing inflammatory non-AIDS comorbidities in PLWH without invasive fungal infection (IFI) [24, 25, 28, 29, 33-36]. We have also shown that plasma BDG levels are associated with reduced expression of Dectin-1 and NKp30 on monocytes and NK cells respectively, indicating direct cellular activation and inflammation by BDG. Circulating BDG contributes to low grade inflammation $[28,37]$ and may enhance trained immunity at the epigenetic level [38, 39]. Therefore, assessment of BDG levels may be useful in predicting the risk of PLWH to develop non-AIDS comorbidities [24-26].
Circulating intestinal fatty acid binding protein (I-FABP) and regenerating islet-derived protein-3 $\alpha$ (REG3 $\alpha$ ) are two validated gut damage markers in PLWH [40, 41]. I-FABP, an intracellular protein constitutively expressed in enterocytes, is released upon cell death and subsequently detected in the blood in inflammatory bowel diseases (IBD) and HIV infection [42, 43]. REG3 $\alpha$, an antimicrobial peptide secreted by intestinal Paneth cells into the gut lumen and upon gut damage, translocates into the blood [41]. We observed that REG3 $\alpha$ plasma levels were correlated with HIV disease progression, microbial translocation and immune activation in PLWH [41].

As levels of gut damage and microbial translocation markers are low in healthy people and significantly elevated in PLWH [44, 45], knowing their daily variations could improve clinical care and research. Herein, we assessed the variation of the microbial translocation markers, LPS and BDG, and the gut damage markers, I-FABP and REG3 $\alpha$, over the course of $24 \mathrm{~h}$ in ARTtreated PLWH in a well-controlled environment.

\section{Methods}

\section{Participants and study design}

In this pilot study, 11 men were recruited as they represent the population most affected by HIV in Canada. Inclusion criteria included men over the age of 50, receiving ART with undetectable viremia for more than 3 years. Participants with opportunistic infections (including fungal infections), co-infection with hepatitis $\mathrm{B}$ or $\mathrm{C}$, chronic colitis or any other acute conditions were excluded. A total of 11 participants were enrolled and hospitalized for $40 \mathrm{~h}$ at the 12-bed phase I clinic of the Centre Hospitalier de l'Université de Montréal, Montréal, QC, Canada. Study timeline is shown in Fig. 1. Blood samples were collected using a catheter fixed to the median cubital vein throughout their hospitalization to prevent repeated venipuncture and disturbing participants' sleep cycles. All the participants were admitted to hospital before 17:00 of the previous day in order for all participants to have the same meal and similar amount of sleep before baseline sampling. Samples were first collected at 8:00 am, and then every $4 \mathrm{~h}$ until 8:00 am the next morning for a total of seven timepoints. Plasma was isolated from whole blood and frozen at $-80{ }^{\circ} \mathrm{C}$. All participants had similar meals/snacks at set times (8:30, 13:00, 16:30 and 20:30), and had a comparable amount of sleep, physical exercise and light exposure. All participants were offered the same meals, with a balance of carbohydrates, proteins, fats and 


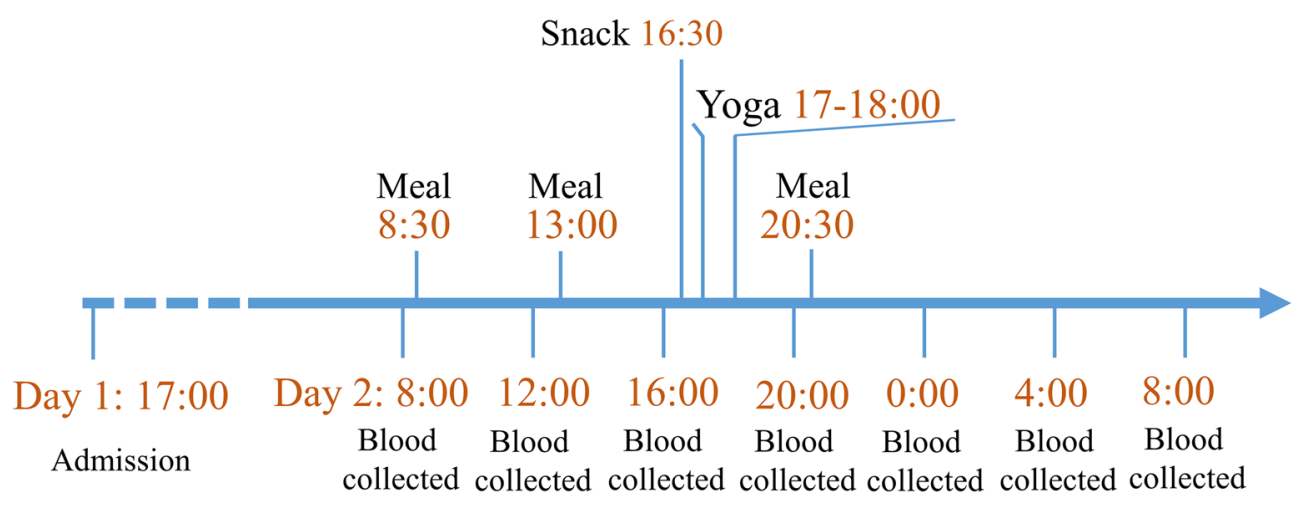

Fig. 1 Study timeline

fibers. Meals did not contain mushrooms nor seaweed. BDG containing foods such as oat bran were not offered to participants. Scientific and artistic educational presentations were organized as part of a knowledge transfer and exchange with participants and research nurses. All participants agreed to take part in a $60 \mathrm{~min}$ low-intensity yoga session in the afternoon. Neither alcoholic beverages nor recreational drugs were permitted during the time of hospitalization.

\section{Laboratory measurements}

Plasma HIV-1 p24 antigen/antibody and confirmatory Western blot tests were used to confirm HIV-infection, as previously reported [28]. Quantification of plasma viral load (VL) was done using the Abbott Real-Time HIV-1 assay (Abbott Laboratories, Abbott Park, Illinois, USA). CD4 and CD8 T-cell counts were measured using flow cytometry. LPS was quantified using a human lipopolysaccharide enzyme-linked immunosorbent assay (ELISA) (Cusabio, Wuhan, China) to avoid cross-reactivity with BDG in existing limulus amebocyte lysate (LAL) assays [28]. Plasma BDG level was measured by the Fungitell ${ }^{\circledR}$ LAL assay (Associates of Cape Cod, Inc., East Falmouth, MA, USA) [28]. I-FABP and REG3 $\alpha$ were quantified in plasma using ELISA (Hycult Biotech, Uden, Netherlands and R\&D systems, Oakville, ON, Canada, respectively) [41].

\section{Statistical analyses}

Statistical analyses were conducted using GraphPad Prism 6.0 (La Jolla, CA, USA). In order to analyze the time variation of parameters while accounting for inter-participant variability, the individual raw data were converted to $\mathrm{Z}$ scores as previously described [46]. Z-scores were calculated by normalizing each datapoint to the mean of the seven timepoints and standard deviation (SD) of the individual according to the formula: (datapoint-mean)/SD.
Comparisons were conducted between timepoints using non-parametric Kruskal-Wallis test with Dunn's post hoc test. An $\alpha$-level of $5 \%$ was used for statistical significance.

\section{Results}

\section{Study participant characteristics}

Participant characteristics were summarized in Table 1. All participants were male, with a median age of 57 years (range 50 to 63). Participants received ART for a median of 17 years (range 13 to 22). Plasma VL of all participants were below the level of detection $(<20$ copies $/ \mathrm{ml})$. Median CD4 T-cell count was 606 (311-1082) cells/ $\mu \mathrm{l}$ and CD8 T-cell count was $613(331-1425)$ cells/ $\mu$ l.

\section{Daily variation of the microbial translocation markers LPS and BDG}

Data are presented as raw concentration of markers at each timepoint (left column), individual participant's Z-score (middle column) and average Z-score (right column). Comparison between time points showed that LPS levels varied significantly over time $(\mathrm{p}<0.001)$ and tended to decrease between 8:00 to 12:00 (Z-score $-0.22 \pm 0.31$ vs. $-1.15 \pm 0.18$ ), without reaching statistical significance (Fig. 2c). A significant increase of LPS was observed from 12:00 to $16: 00$ (Z-score of $-1.15 \pm 0.18$ vs. $0.16 \pm 0.15$, $\mathrm{p}=0.02$ ) (Fig. 2c). Similarly, a difference was also noticed between 12:00 and 24:00 (Z-score of $-1.15 \pm 0.18$ vs. $0.89 \pm 0.26, \mathrm{p}<0.001$ ) (Fig. 2c). At 8:00 on the second day, levels of LPS were comparable to levels observed at 8:00 on the preceding day (Fig. 2c).

Conversely, levels of BDG did not vary significantly over the course of the study (Fig. $2 \mathrm{~d}-\mathrm{f}, \mathrm{p}=0.261$ ).

\section{Daily variation of the gut damage markers I-FABP and REG3a}

Over the course of the study, I-FABP levels varied significantly $(\mathrm{p}<0.001)$. I-FABP levels decreased from 8:00 
Table 1 Participant characteristics $(n=11)$

\begin{tabular}{llllllll}
\hline ID & Age & $\begin{array}{l}\text { Body mass } \\
\text { index }\left(\mathbf{k g} / \mathbf{m}^{\mathbf{2}}\right)\end{array}$ & $\begin{array}{l}\text { CD4 count } \\
(\mathbf{c e l l} \mathbf{s} / \boldsymbol{\mu L})\end{array}$ & $\begin{array}{l}\text { CD8 counts } \\
(\mathbf{c e l l s} / \boldsymbol{\mu L})\end{array}$ & $\begin{array}{l}\text { ART duration } \\
\text { (years) }\end{array}$ & Viral load & Current ART medication \\
\hline 1 & 60 & 27.8 & 602 & 1321 & 10 & Undetectable & Emtricitabine, TDF, raltegravir \\
2 & 52 & 27.1 & 491 & 613 & 21 & Undetectable & Emtricitabine, TDF, raltegravir \\
3 & 57 & 28.4 & 606 & 855 & 12 & Undetectable & Emtricitabine, TDF, raltegravir \\
4 & 57 & 32.9 & 846 & 901 & 22 & Undetectable & Emtricitabine, TDF, darunavir, cobicistat \\
5 & 57 & 24.9 & 410 & 924 & 31 & Undetectable & Emtricitabine, TDF, efavirenz \\
6 & 63 & 27.7 & 667 & 553 & 15 & Undetectable & Abacavir, dolutegravir, lamivudine \\
7 & 50 & 34.9 & 379 & 498 & 19 & Undetectable & Emtricitabine, TDF, raltegravir \\
8 & 58 & 26.1 & 311 & 331 & 21 & Undetectable & Emtricitabine, TDF, elvitegravir, cobicistat \\
9 & 57 & 24.6 & 800 & 597 & 13 & Undetectable & Abacavir, dolutegravir, lamivudine \\
10 & 58 & 32.1 & 675 & 494 & 13 & Undetectable & Abacavir, dolutegravir, lamivudine \\
11 & 54 & 23.9 & 1082 & 1425 & 17 & Undetectable & Lamivudine, abacavir, raltegravir \\
\hline
\end{tabular}

TDF, tenofovir disoproxil fumarate

to $16: 00$ with a Z-score $0.48 \pm 0.26$ vs. $-0.92 \pm 0.09$ $(p=0.002)$ (Fig. 2i). After 16:00, levels of I-FABP increased [Z-score of $0.73 \pm 0.27$ at 4:00 $(\mathrm{p}<0.001)$ and $0.88 \pm 0.27$ at 8:00 $(\mathrm{p}<0.001)]$. Similar levels of I-FABP were observed at 8:00 of the first day and 8:00 of the second day ( $\mathrm{p}>0.05)$ (Fig. $2 \mathrm{~g}$ ).

Levels of the gut damage marker REG3 $\alpha$ did not vary significantly over the course of the study (Fig. 2J-l, $\mathrm{p}=0.570)$.

\section{Discussion}

We observed a daily variation of plasma I-FABP with a median difference of $2060 \mathrm{pg} / \mathrm{ml}$ between the highest and lowest values, representing a 4.2-fold intraday variation. The median plasma LPS range between highest and lowest values was $18 \mathrm{pg} / \mathrm{mL}$, representing a 1.6fold intraday change. Such variations might explain the breadth of I-FABP and LPS levels observed in other ARTtreated PLWH studies where time of sampling was not documented or considered [13, 28, 41]. Previous work in mouse models has shown a postprandial increase in LPS levels [47]. We observed a clinically relevant decrease of LPS after breakfast and an increase after dinner which might be explained by natural variations in circadian rhythm $[48,49]$. These results suggest that sampling LPS from fasting PLWH might decrease variation throughout the day. Similarly, I-FABP was subject to daily variations with the lowest level at 16:00 and highest at 4:00-8:00. However, plasma levels of BDG and REG3 $\alpha$ showed no significant variation and were not affected by food intake, time of sampling, or day/night shifts. These findings further validate the use of BDG and REG3 $\alpha$ as markers of microbial translocation and gut damage, respectively in ART-treated PLWH.
Translocation of bacterial and fungal products is driven by epithelial gut damage and depletion of intestinal CD4-T cells and contributes to immune activation in HIV $[35,50]$. Clinical studies commonly use circulating I-FABP to evaluate gut damage as a measure of enterocyte cell lysis. However, in the absence of enterocyte lysis, I-FABP poorly correlates with microbial translocation [41]. Our results show that circulating I-FABP levels varied greatly throughout the course of a day, which limits its value as a marker of gut damage, since it is dependent on the time of sampling and fasting status. In contrast to I-FABP, REG3 $\alpha$ appeared stable over the course of $24 \mathrm{~h}$. Therefore, our results and previous work favor REG3 $\alpha$ as a reliable gut damage marker independent of sampling time and food intake in PLWH [41].

LPS is a bacterial translocation marker, responsible for chronic immune activation in HIV-infected patients [51]. However, increasing evidence indicates that diet and food intake affect the plasma level of LPS in mouse and human models. Cani et al. [47] first reported in 2007 that plasma levels of LPS increased after feeding mice with a high-fat diet. Furthermore, López-Moreno et al. [52] reported that the consumption of diet rich in saturated fat increased plasma levels of LPS which in turn, increase the postprandial inflammatory response in subjects with metabolic syndrome. Our results also indicated that food intake was associated with an increase in plasma level of LPS in ART-treated PLWH up to 4 hours after lunch and supper. Although the underlying mechanism is unclear, it may be related to changes in microbiota composition, increases in the proportion of LPS producing Gramnegative bacteria in the presence of nutrients [53]. LPS detoxification by the intestinal alkaline phosphatase [54], or fat intake promoting gut translocation of LPS [47, 52]. Therefore, monitoring LPS levels in PLWH should 

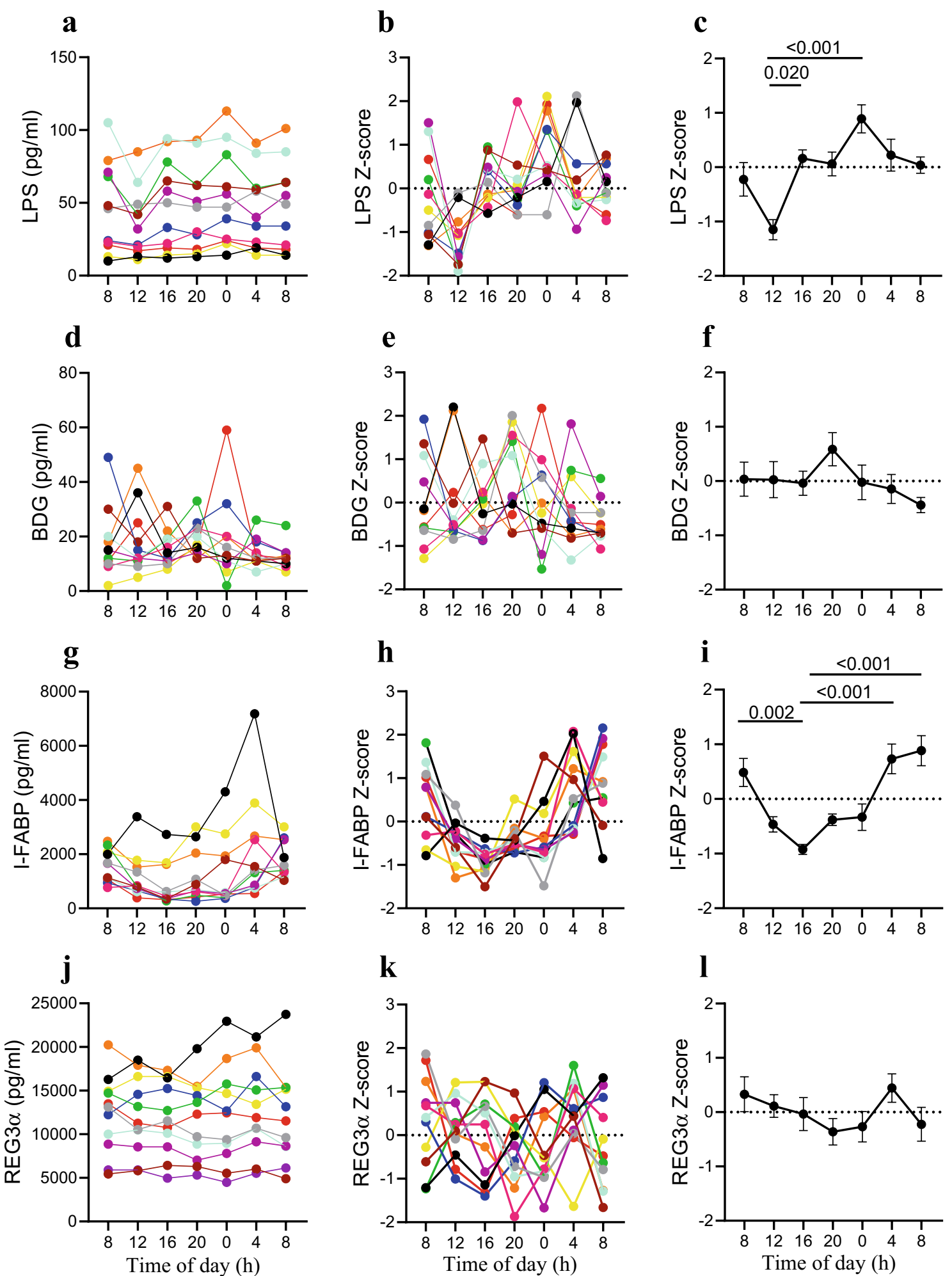

Fig. 2 Daily variation of gut damage and translocation markers. Plasma levels of Lipopolysaccharide (LPS) (a-c, $p<0.001),(1 \rightarrow 3)-\beta$-D-Glucan $(B D G)(\mathbf{d}-\mathbf{f}, p=0.261)$, Intestinal fatty acid binding protein (I-FABP) $(\mathbf{g}-\mathbf{i}, p<0.001)$ or Regenerating islet-derived protein $3 a(R E G 3 a)(\mathbf{j}-\mathbf{I}, p=0.570)$. In figure a-k, different colors represent different participants: red (ID 1); orange (ID 2); yellow (ID 3); green (ID 4); blue (ID 5); cyan (ID 6); purple (ID 7); pink (ID 8); gray (ID 9); black (ID 10); brown (ID 11). Mean \pm standard error of the mean (SEM) of the Z-score are shown in (c, $\mathbf{f}, \mathbf{i}, \mathbf{I})$. Friedman test 
take into account feeding state and time of specimen acquisition.

Unlike LPS, we showed that the fungal translocation marker BDG is stable throughout the day and independent of food intake. BDG can be found in food such as mushroom and seaweed $[55,56]$. Interestingly, Hashimoto et al. reported that serum BDG value was elevated due to intake of seaweed in a hematopoietic stem cell transplant recipient [57]. However, the elevation of BDG may have been linked to gut damage with increased intestinal permeability during acute graft-versus-host disease (GVHD). Nevertheless, our results showed that BDG is a reliable marker for fungal translocation in ART-treated PLWH. The food provided in our study did not comprise mushroom, seaweed or other material rich of BDG. Thus, further studies need be conducted in order to study the effects of BDG rich food on its plasma level.

We acknowledge that our study presents some limitations as we did not study the underlying mechanism of daily variation of I-FABP or LPS levels. Daily changes in the external environment may also influence those markers and studies have identified the molecular underpinnings of oscillations in circadian clock gene expression occurring over the 24-hour day [49]. Our study population only included a small sample size of male participants over the age of 50 , therefore younger participants and inclusion of female participants will be needed to generalize study findings to a larger population, compared to a HIV-uninfected control group.

\section{Conclusion}

To our knowledge, we are the first to report the daily variation of different microbial translocation with gut damage markers in ART-treated PLWH. We showed that conversely to I-FABP and LPS, plasma levels of REG3 $\alpha$ and BDG can be considered as reliable markers of gut damage and fungal translocation respectively, and are not influenced by food intake, time of sampling, or day/night shifts. Our findings provide reference for clinical research, focusing on the assessment of blood markers of gut damage and microbial translocation. The clinical implications of the daily variation of these markers should be assessed in larger cohorts of ART-treated $\mathrm{PLWH}$, including male and female participants from different ages and ethnicity.

\section{Abbreviations}

ART: Antiretroviral therapy; LPS: Lipopolysaccharide; BDG: ( $\rightarrow$ 3)- $\beta$-D-Glucan; GVHD: Graft-versus-host disease; LAL: Limulus amebocyte lysate; IBD: Inflammatory bowel diseases; I-FABP: Intestinal fatty acid binding protein; IFI: Invasive fungal infection; PAMP: Pathogen-associated molecular pattern; PLWH: people living with HIV; REG3a: Regenerating islet-derived protein-3a; SD: Standard deviation; VL: Viral load.

\section{Acknowledgements}

We are highly grateful to the study participants for their contribution. We thank Josée Girouard, Angie Massicotte and Guillaume Theriault for study coordination and assistance. We also thank Mario Legault (CRCHUM) for IRB approvals and Lucie Fuzeau (CRCHUM) for patient hospitalisation management.

\section{Authors' contributions}

JO, SI wrote the manuscript. JO, SI, JL and BF participated in laboratory testing, statistical analysis, and drafting of the manuscript. DC, TRWS, DP, AF, AC, EMG, LRM performed isolation of plasma and PBMC during the study. YZ and MF performed the Fungitell assay. YC, DEK, NC, PA and JPR conceived and designed the study. All authors read and approved the final manuscript.

\section{Funding}

This study was supported by grants from the Canadian Institutes of Health Research (CIHR) (PJT-153052 to PA). TRWS and DP received Doctoral awards from the Université de Montréal and the FRQ-S. JPR holds a Louis Lowenstein Chair in Hematology and Oncology, McGill University. Core facilities and HIVinfected patients' cohorts were supported by the Fondation du CHUM and the FRQ-S Network.

\section{Availability of data and materials}

The datasets during and/or analysed during the current study available from the corresponding author on reasonable request.

\section{Ethics approval and consent to participate}

The study was approved by the ethical committee of the McGill University Health Centre (MUHC, number MEO-02-2019-4872) and the Centre Hospitalier de l'Université de Montréal (CHUM, number MP-02-2017-6677). All study participants provided written consent for enrollment before participation. The study was conducted in accordance with the declaration of Helsinki.

\section{Consent for publication}

Not applicable.

\section{Competing interests}

The authors declare that they have no competing interests.

\section{Author details}

${ }^{1}$ Infectious Diseases and Immunity in Global Health Program, Research Institute, McGill University Health Centre, 1001 Blvd Décarie, Montreal, QC, Canada. ${ }^{2}$ Chronic Viral Illness Service, McGill University Health Centre, Montreal, QC, Canada. ${ }^{3}$ Chongqing Public Health Medical Center, Chongqing, China. ${ }^{4}$ Department of Microbiology and Immunology, McGill University, Montreal, QC, Canada. ${ }^{5}$ Centre de Recherche du Centre Hospitalier de l'Université de Montréal (CRCHUM), Montréal, QC, Canada. ${ }^{6}$ Département de Microbiologie, Infectiologie et Immunologie, Faculté de Médecine, Université de Montréal, Montréal, QC, Canada. ${ }^{7}$ Associates of Cape Cod Inc, Falmouth, MA, USA.

${ }^{8}$ Douglas Research Centre, Department of Psychiatry, McGill University, Montréal, QC, Canada. ${ }^{9}$ Division of Hematology, McGill University Health Centre, Montreal, QC, Canada.

Received: 24 January 2020 Accepted: 4 May 2020

Published online: 12 May 2020

\section{References}

1. Cao W, Mehraj V, Vyboh K, Li T, Routy JP. Antiretroviral therapy in primary HIV-1 infection: influences on immune activation and gut mucosal barrier dysfunction. AIDS Rev. 2015;17(3):135-46.

2. Vyboh $\mathrm{K}$, Jenabian MA, Mehraj V, Routy JP. HIV and the gut microbiota, partners in crime: breaking the vicious cycle to unearth new therapeutic targets. J Immunol Res. 2015;2015:614127.

3. Wacleche VS, Landay A, Routy JP, Ancuta P. The Th17 lineage: from barrier surfaces homeostasis to autoimmunity, cancer, and HIV-1 pathogenesis. Viruses. 2017:9(10):303.

4. Hensley-McBain T, Berard AR, Manuzak JA, Miller CJ, Zevin AS, Polacino $P$, et al. Intestinal damage precedes mucosal immune dysfunction in SIV infection. Mucosal Immunol. 2018;11(5):1429-40. 
5. Godfrey C, Bremer A, Alba D, Apovian C, Koethe JR, Koliwad S, et al. Obesity and fat metabolism in human immunodeficiency virus-infected individuals: immunopathogenic mechanisms and clinical implications. J Infect Dis. 2019;220(3):420-31.

6. Jenabian MA, El-Far M, Vyboh K, Kema I, Costiniuk CT, Thomas R, et al. Immunosuppressive tryptophan catabolism and gut mucosal dysfunction following early HIV infection. J Infect Dis. 2015;212(3):355-66.

7. Estrada V, Gonzalez N. Gut microbiota in diabetes and HIV: inflammation is the link. EBioMedicine. 2018:38:17-8.

8. Hoel H, Hove-Skovsgaard M, Hov JR, Gaardbo JC, Holm K, Kummen M, et al. Impact of HIV and type 2 diabetes on gut microbiota diversity, tryptophan catabolism and endothelial dysfunction. Sci Rep. 2018;8(1):6725.

9. Moon JY, Zolnik CP, Wang Z, Qiu Y, Usyk M, Wang T, et al. Gut microbiota and plasma metabolites associated with diabetes in women with, or at high risk for. HIV infection. EBioMedicine. 2018;37:392-400.

10. Morou A, Brunet-Ratnasingham E, Dube M, Charlebois R, Mercier E, Darko $\mathrm{S}$, et al. Altered differentiation is central to HIV-specific CD4(+) T cell dysfunction in progressive disease. Nat Immunol. 2019;20(8):1059-70.

11. Reid MJA, Ma Y, Golovaty I, Okello S, Sentongo R, Feng M, et al. Association of gut intestinal integrity and inflammation with insulin resistance in adults living with HIV in Uganda. AIDS Patient Care STDS 2019;33(7):299-307.

12. Ancuta P, Kamat A, Kunstman KJ, Kim EY, Autissier P, Wurcel A, et al. Microbial translocation is associated with increased monocyte activation and dementia in AIDS patients. PLoS ONE. 2008;3(6):e2516.

13. Brenchley JM, Price DA, Schacker TW, Asher TE, Silvestri G, Rao S, et al. Microbial translocation is a cause of systemic immune activation in chronic HIV infection. Nat Med. 2006;12(12):1365-71.

14. Cassol E, Misra V, Holman A, Kamat A, Morgello S, Gabuzda D. Plasma metabolomics identifies lipid abnormalities linked to markers of inflammation, microbial translocation, and hepatic function in HIV patients receiving protease inhibitors. BMC Infect Dis. 2013;13:203.

15. Epeldegui M, Magpantay L, Guo Y, Halec G, Cumberland WG, Yen PK, et al. A prospective study of serum microbial translocation biomarkers and risk of AIDS-related non-Hodgkin lymphoma. AIDS. 2018;32(7):945-54.

16. Fitzgerald FC, Lhomme E, Harris K, Kenny J, Doyle R, Kityo C, et al. Microbial translocation does not drive immune activation in Ugandan children infected with HIV. J Infect Dis. 2019;219(1):89-100.

17. George V, Harrison L, Roach M, Li XD, Tierney C, Fischl MA, et al. Associations of plasma cytokine and microbial translocation biomarkers with immune reconstitution inflammatory syndrome. J Infect Dis. 2017;216(9):1159-63.

18. Marchetti G, Cozzi-Lepri A, Merlini E, Bellistri GM, Castagna A, Galli M, et al. Microbial translocation predicts disease progression of HIVinfected antiretroviral-naive patients with high CD4+ cell count. AIDS. 2011;25(11):1385-94.

19. Pedersen KK, Pedersen M, Troseid M, Gaardbo JC, Lund TT, Thomsen $C$, et al. Microbial translocation in HIV infection is associated with dyslipidemia, insulin resistance, and risk of myocardial infarction. J Acquir Immune Defic Syndr. 2013;64(5):425-33.

20. Reid M, Ma Y, Scherzer R, Price JC, French AL, Huhn GD, et al. Contribution of liver fibrosis and microbial translocation to immune activation in persons infected with HIV and/or Hepatitis C virus. J Infect Dis. 2018;217(8):1289-97.

21. Sacchi P, Cima S, Corbella M, Comolli G, Chiesa A, Baldanti F, et al. Liver fibrosis, microbial translocation and immune activation markers in HIV and HCV infections and in HIV/HCV co-infection. Dig Liver Dis. 2015;47(3):218-25.

22. Steele AK, Lee EJ, Vestal B, Hecht D, Dong Z, Rapaport E, et al. Contribution of intestinal barrier damage, microbial translocation and HIV-1 infection status to an inflammaging signature. PLoS ONE. 2014;9(5):e97171

23. Troseid M, Manner IW, Pedersen KK, Haissman JM, Kvale D, Nielsen SD. Microbial translocation and cardiometabolic risk factors in HIV infection. AIDS Res Hum Retroviruses. 2014:30(6):514-22.

24. Gianella S, Letendre SL, ludicello J, Franklin D, Gaufin T, Zhang Y, et al. Plasma ( $\longrightarrow$ 3)-beta-D-glucan and suPAR levels correlate with neurocognitive performance in people living with HIV on antiretroviral therapy: a CHARTER analysis. J Neurovirol. 2019;25:837-43.

25. Hoenigl M, de Oliveira MF, Perez-Santiago J, Zhang Y, Morris S, McCutchan AJ, et al. (1->3)-beta-D-Glucan levels correlate with neurocognitive functioning in HIV-infected persons on suppressive antiretroviral therapy: a cohort study. Medicine (Baltimore). 2016;95(11):e3162.

26. Hoenigl M, Moser CB, Funderburg N, Bosch R, Kantor A, Zhang Y, EugenOlsen J, Finkelman M, Reiser J, Landay A, Moisi D. Soluble urokinase plasminogen activator receptor is predictive of non-aids events during antiretroviral therapy-mediated viral suppression. Clin Infect Dis. 2018;69:676-86.

27. Weiner LD, Retuerto M, Hager CL, El Kamari V, Shan L, Sattar A, et al. Fungal translocation is associated with immune activation and systemic inflammation in treated HIV. AIDS Res Hum Retroviruses. 2019;35(5):461-72.

28. Mehraj V, Ramendra R, Isnard S, Dupuy FP, Ponte R, Chen J, et al. Circulating (1->3)-beta-D-glucan is associated with immune activation during human immunodeficiency virus infection. Clin Infect Dis. 2020;70(2):232-41.

29. Hoenigl M, Perez-Santiago J, Nakazawa M, de Oliveira MF, Zhang Y, Finkelman MA, et al. (1 $\longrightarrow$ 3)-beta-d-Glucan: a biomarker for microbial translocation in individuals with acute or early HIV infection? Front Immunol. 2016;7:404

30. Mirzaei MK, Maurice CF. Menage a trois in the human gut: interactions between host, bacteria and phages. Nat Rev Microbiol. 2017;15(7):397-408

31. Limper AH, Adenis A, Le T, Harrison TS. Fungal infections in HIV/AIDS. Lancet Infect Dis. 2017;17(11):e334-43.

32. Kang X, Kirui A, Muszynski A, Widanage MCD, Chen A, Azadi P, et al. Molecular architecture of fungal cell walls revealed by solid-state NMR. Nat Commun. 2018;9(1):2747.

33. Farhour Z, Mehraj V, Chen J, Ramendra R, Lu H, Routy JP. Use of $(1 \longrightarrow 3)$-beta-d-glucan for diagnosis and management of invasive mycoses in HIV-infected patients. Mycoses. 2018;61 (10):718-22.

34. Hoenigl M, de Oliveira MF, Perez-Santiago J, Zhang Y, Woods SP, Finkelman M, et al. Correlation of ( $1 \longrightarrow 3$ )-beta-D-glucan with other inflammation markers in chronically HIV infected persons on suppressive antiretroviral therapy. GMS Infect Dis. 2015. https://doi.org/10.3205/id000 018.

35. Hoenigl M. Fungal translocation: a driving force behind the occurrence of non-aids events? Clin Infect Dis. 2020;70(2):242-4.

36. Dirajlal-Fargo S, Moser C, Rodriguez K, El-Kamari V, Funderburg NT, Bowman $E$, et al. Changes in the fungal marker beta-D-Glucan after antiretroviral therapy and association with adiposity. Open Forum Infect Dis. 2019;6(11):ofz434.

37. Morris A, Hillenbrand M, Finkelman M, George MP, Singh V, Kessinger $C$ et al. Serum (1->3)-beta-D-glucan levels in HIV-infected individuals are associated with immunosuppression, inflammation, and cardiopulmonary function. J Acquir Immune Defic Syndr. 2012;61(4):462-8.

38. Netea MG, Dominguez-Andres J, Barreiro LB, Chavakis T, Divangahi $M$, Fuchs $E$, et al. Defining trained immunity and its role in health and disease. Nat Rev Immunol. 2020. https://doi.org/10.1038/s4157 7-020-0285-6.

39. Namakula R, de Bree LCJ, Tvedt TH, Netea MG, Cose S, Hanevik K. Monocytes from neonates and adults have a similar capacity to adapt their cytokine production after previous exposure to BCG and beta-glucan. PLOS ONE. 2020:15(2):e0229287.

40. Cheru LT, Park EA, Saylor CF, Burdo TH, Fitch KV, Looby S, et al. I-FABP is higher in people with chronic HIV than elite controllers, related to sugar and fatty acid intake and inversely related to body fat in people with HIV. Open Forum Infect Dis. 2018;5(11):ofy288.

41. Isnard S, Ramendra R, Dupuy FP, Lin J, Fombuena B, Kokinov N, et al. Plasma levels of C-Type Lectin REG3alpha and gut damage in people with human immunodeficiency virus. J Infect Dis. 2020;221(1):110-21.

42. Al-Saffar AK, Meijer CH, Gannavarapu VR, Hall G, Li Y, Diaz Tartera HO, et al. Parallel changes in harvey-bradshaw index, TNFalpha, and intestinal fatty acid binding protein in response to infliximab in Crohn's Disease. Gastroenterol Res Pract. 2017;2017:1745918.

43. Adriaanse MP, Tack GJ, Passos VL, Damoiseaux JG, Schreurs MW, van Wijck $\mathrm{K}$, et al. Serum I-FABP as marker for enterocyte damage in coeliac disease and its relation to villous atrophy and circulating autoantibodies. Aliment Pharmacol Ther. 2013;37(4):482-90.

44. Isnard S, Ramendra R, Dupuy FP, Lin J, Fombuena B, Kokinov N, et al. Plasma levels of C-type lectin REG3alpha and gut damage in people with HIV. J Infect Dis. 2020;221(1):110-21. 
45. Mehraj V, Ramendra R, Isnard S, Dupuy FP, Ponte R, Chen J, et al. Circulating $(1 \longrightarrow 3)$-beta-D-Glucan is associated with immune activation during human immunodeficiency virus infection. Clin Infect Dis. 2020;70(2):232-41.

46. Koshy A, Cuesta M, Boudreau P, Cermakian N, Boivin DB. Disruption of central and peripheral circadian clocks in police officers working at night. FASEB J. 2019:33(6):6789-800.

47. Cani PD, Amar J, Iglesias MA, Poggi M, Knauf C, Bastelica D, et al. Metabolic endotoxemia initiates obesity and insulin resistance. Diabetes. 2007;56(7):1761-72.

48. Summa KC, Voigt RM, Forsyth CB, Shaikh M, Cavanaugh K, Tang Y, et al. Disruption of the circadian clock in mice increases intestinal permeability and promotes alcohol-induced hepatic pathology and inflammation. PLoS ONE. 2013;8(6):e67102.

49. Gachon F, Yeung J, Naef F. Cross-regulatory circuits linking inflammation, high-fat diet, and the circadian clock. Genes Dev. 2018;32(21-22):1359-60.

50. Dirajlal-Fargo S, El-Kamari V, Weiner L, Shan L, Sattar A, Kulkarni M, et al. Altered intestinal permeability and fungal translocation in Ugandan children with HIV. Clin Infect Dis. 2019. https://doi.org/10.1093/cid/ciz561.

51. Vassallo M, Mercie P, Cottalorda J, Ticchioni M, Dellamonica P. The role of lipopolysaccharide as a marker of immune activation in HIV-1 infected patients: a systematic literature review. Virol J. 2012;9:174.

52. Lopez-Moreno J, Garcia-Carpintero S, Jimenez-Lucena R, Haro C, RangelZuniga OA, Blanco-Rojo R, et al. Effect of dietary lipids on endotoxemia influences postprandial inflammatory response. J Agric Food Chem. 2017;65(35):7756-63.

53. Hrncir T, Stepankova R, Kozakova H, Hudcovic T, Tlaskalova-Hogenova H. Gut microbiota and lipopolysaccharide content of the diet influence development of regulatory T cells: studies in germ-free mice. BMC Immunol. 2008;9:65.

54. Geddes K, Philpott DJ. A new role for intestinal alkaline phosphatase in gut barrier maintenance. Gastroenterology. 2008;135(1):8-12.

55. Vetvicka V, Dvorak B, Vetvickova J, Richter J, Krizan J, Sima P, et al. Orally administered marine ( $1 \longrightarrow 3$ )-beta-D-glucan Phycarine stimulates both humoral and cellular immunity. Int J Biol Macromol. 2007;40(4):291-8.

56. Samuelsen ABC, Rise F, Wilkins AL, Teveleva L, Nyman AAT, Aachmann FL. The edible mushroom Albatrellus ovinus contains a alpha-l-fuco-alphad-galactan, alpha-d-glucan, a branched $(1 \longrightarrow 6)$-beta-d-glucan and a branched (1 $\longrightarrow$ 3)-beta-d-glucan. Carbohydr Res. 2019;471:28-38.

57. Hashimoto N, Mori T, Hashida R, Sakurai M, Koda Y, Toyama T, et al. Falsepositive serum (1,3)-beta-D-glucan elevation due to intake of seaweed in a hematopoietic stem cell transplant recipient. Transpl Infect Dis. 2017;19(2):12653.

\section{Publisher's Note}

Springer Nature remains neutral with regard to jurisdictional claims in published maps and institutional affiliations.
Ready to submit your research? Choose BMC and benefit from:

- fast, convenient online submission

- thorough peer review by experienced researchers in your field

- rapid publication on acceptance

- support for research data, including large and complex data types

- gold Open Access which fosters wider collaboration and increased citations

- maximum visibility for your research: over $100 \mathrm{M}$ website views per year

At BMC, research is always in progress.

Learn more biomedcentral.com/submissions 